\title{
Preface for the special issue of the 1st Saudi-Chinese Oil Refinery Forum (1st SCORF 2013)
}

\author{
Zi-Feng Yan $\cdot$ Hamid A. Al-Megren
}

(C) The Author(s) 2014. This article is published with open access at Springerlink.com

The continuous increasing of heavier crude oil supply and regulatory pressure for environmentally more acceptable oil products puts forwards ever more critical requirements on oil refining industry. The fast economic development in China leads to ever-increasing consumption of refined oil products and refining capacity and makes China world's second largest oil refiner, consuming 488 million tons of crude oil in 2013. As one of the most important oil processing, fluid catalytic cracking (FCC) is of great significance in converting heavy oil into high-octane gasoline, diesel and liquefied petroleum gas (LPG). In China, about $75-80 \%$ of gasoline and more than $40 \%$ of diesel come from FCC products. Currently, the FCC modified processes provide approximately one-third of the world's propylene.

In Saudi Arabia, Saudi Aramco is a fully integrated, global petroleum enterprise and a world leader in exploration and producing, refining, distribution, shipping and marketing. The company manages the largest proven reserves of conventional crude oil, 260.1 billion barrels, and the fourth-largest gas reserves in the world, 275.2 trillion cubic feet. Saudi Arabia, the world's biggest crude exporter, also expects to become the top single refiner producer of refined products such as fuel and petrochemicals. Saudi Arabia oil refinery capacity is at a current level of $2.122 \mathrm{Mbpd}$, up from 2.107 Mbpd 2 years ago. Saudi Arabia could consume nearly a tenth of the kingdom's

\section{Z.-F. Yan}

State Key Laboratory of Heavy Oil Processing, CNPC Key Laboratory of Catalysis, China University of Petroleum, Qingdao, China

\section{H. A. Al-Megren ( $\square)$}

Petrochemical Research Institute, King Abdulaziz City for Science and Technology, Riyadh, Saudi Arabia

e-mail: almegren@kacst.edu.sa current production capacity of about 12.0 million bpd when they are all fully operational in 2017.

Environmental protection nowadays has been a general consensus worldwide and environmentally driven regulations are also requiring significant improvement in the quality of gasoline and diesel in many parts of the world. Reducing organic sulfur content in gasoline has been recognized as one way of reducing emission of sulfur oxides. In China, the sulfur content in gasoline is required as low as $150 \mathrm{ppm}$ since 2006 and further reduced to be less than $50 \mathrm{ppm}$ since 2011. In the case of gasoline pool, nearly $90 \%$ of sulfur content comes from FCC gasoline in China and about $33 \%$ in USA. Therefore, refineries' efforts focus on effectively reducing the sulfur species coming from FCC unit by already existing technologies or developing more efficient and economical methods.

Saudi refineries are also busy improving products' quality by reducing sulfur in gasoline and diesel and reducing benzene in gasoline to improve local environment and to maintain competitiveness in international markets. Saudi Arabia has been leading the regional shift by working to implement projects that will improve gasoline and diesel qualities. To comply with mandatory sulfur specifications for gasoline and diesel between 2013 and 2016, the Kingdom of Saudi Arabia plans to construct multiple clean-fuel projects that will improve gasoline and diesel qualities. Saudi Arabia is seeking to reduce sulfur content in diesel and gasoline to 10 parts per million (ppm) and to lower benzene content in gasoline to $1 \%$. With these new fuel specifications, Saudi Arabian refining operations will comply with international standards. This will represent a dramatic reduction in sulfur levels from 2012, when Saudi Arabia's maximum sulfur level for diesel was greater than $500 \mathrm{ppm}$. The planned upgrades 
and revamps are necessary to meet future market demand for higher-value, lower-sulfur transportation fuels.

As the crude oils are getting heavier and the demand for high value petroleum products is increasing, FCC technologies are developing under the following directions: (a) reducing the yields of dry gas and coke, and increasing the yield of light oil; (b) increasing the diesel to gasoline ratio of the product; (c) increasing the processing capacity of inferior feedstock; (d) improving the product quality; and (e) increasing the yield of light olefins. Catalysts technology is the core for oil refining industry. In the year 2013, the estimated value of worldwide refining catalysts is approximately US\$ 3.13 trillion while the value of FCC catalysts is close to US\$ 0.91 trillion. In the past decades, refineries and catalyst companies in China have developed scores of new FCC catalysts (categories such as Orbit, LB, LVR-60, CC-20D) for heavy oil conversion to more light oil yields and resisting coking and metal contamination, FCC catalysts (categories such as GOR, LGO, LBO, LHO-1) special for decreasing olefin production, and FCC catalyst additives (categories such as $\mathrm{CHO}, \mathrm{CA}, \mathrm{LBO}-\mathrm{A}$, MS-011) special for more propylene, improving octane numbers of FCC gasoline or decreasing sulfur content of FCC gasoline.

Besides, the FCC unit technologies have also been developed to adapt the request of FCC catalysts and feedstock. One of the most successful examples is the twostage riser (TSR) FCC technology developed by China University of Petroleum. In 2002, the TSR FCC technology was firstly commercially applied in a $100 \mathrm{kt} / \mathrm{a}$ industrial unit. After the technological renovation and transformation, the dry gas and coke yields decreased $2.7 \mathrm{wt} \%$ while the liquid products yield increased $2.7 \mathrm{wt} \%$. Moreover, the cetane number of diesel increased 7 units. At present, there are 12 industrial units, including that in the stage of transformation or new construction, applied the TSR technology. The accumulative processing capacity has reached $9 \mathrm{Mt} / \mathrm{a}$, the processing capacity of the largest unit is $1.6 \mathrm{Mt} / \mathrm{a}$.

The 1st Saudi-Chinese Oil Refinery Forum (1st SCORF 2013), organized by King Abdul Aziz City for Science and Technology (KACST) in Riyadh with cooperation with China University of Petroleum (CUP), provided an opportunity for oil refinery key players to meet and discuss the latest developments in refinery technologies, innovative catalysts and sulfur management in refinery process, FCC process, development, and upgrading of crude oil and heavy residues, integrations of refining and petrochemical processes and hydro-processing of crude oil fractions.

This special issue presents selected papers from the conference (1st SCORF 2013) pertinent to catalyst preparation, modification and characterization, catalytic reactions, new advances in environmental technologies, and refining technologies and new processing plants. The papers have been subject to an initial screening process by the conference organizers and then a normal peer-review process. The following highlights may be as a general summary of the topics in this issue.

In China, the needs for effective and efficient conversion of heavy oils have necessitated persistent high interest in research and development of refining catalysts, both focused on FCC catalyst active components and matrix materials. The $\mathrm{Y}$ zeolite is a single largest catalyst employed worldwide as FCC active component and 30$50 \%$ of all motor fuels in the last decades have been produced using Y zeolite catalysts. Presently, one focus is the rare-earth modification of $\mathrm{Y}$ to modulate its acidity and cracking activity. The papers on "Research on the high activity of REY zeolite in fluid catalytic cracking reaction" and "The development of FCC catalysts for producing FCC gasoline with high octane numbers" present the importance of rare earth in modification of the acidity and pore properties of USY and improvement of VGO conversion. Besides, another paper titled "The application of mesoporous alumina with rich Brönsted acidic sites in FCC catalysts" offers an innovative idea to reduce coke yield and increase FCC feed conversion by modification of alumina matrix, on which the cracking active sites of Brönsted acidic sites are introduced while coking inclined Lewis acidic sites are reduced by a simple sol-gel method.

Besides, zeolites are also used in other refining processes such as hydroisomerization and hydrocracking. Coincidentally, facing the same thorny problems of diffusion and effective contact of bigger hydrocarbon molecules on active sites in microporous zeolites, an innovation is to improve the accessibility by preparing micro-/mesoporous composite zeolites. From the laboratory of China University of Petroleum, efforts directed to the reconstruction and/ or post-treatment of commercial zeolites for hierarchical zeolites SAPO-11 and USY are described, respectively, contributed by $\mathrm{H}$. Song et al. and $\mathrm{X}$. Li, et al.

About $75-80 \%$ of gasoline and $30-40 \%$ of diesel comes from FCC products in China. Therefore, it has enormous economic and social benefits to convert heavier crude oils into high value petroleum products. One of the greatest progresses in the past decade in China is the development and intensively industrial applications of twostage riser (TSR) FCC process, which can be operated in different modes for market demands. The paper "Multifunctional two-stage riser fluid catalytic cracking process" describes the TSR FCC process for maximizing light oil and its development for increasing diesel yield, enhancing the conversion of heavy oil, and reducing the olefin content of gasoline. In this special issue, another innovation for FCC unit is described by Dr. R. Partha, who concentrated in his scientific paper on "HS-FCC" ${ }^{\mathrm{TM}}$ high-severity 
fluidized catalytic cracking: A newcomer to the FCC family" that is considered a breakthrough technology in the refining and petrochemical industry. HS-FCC produces four times more light olefins with minimum gasoline loss and produces high-octane gasoline as well. Full-scale commercial unit study for 30,000 BPSD HS-FCC plant was completed in 2012.

In China, the critical requirements for community health and pollution control and prevention have gained national attention in the light of increasingly serious air pollution caused by the use of fossil fuel. Sulfur abatement and sulfur managements have been a critical issue of laboratory and refinery for several years. In this special issue, the paper on "Additives for in situ reduction of sulfur in fluid catalytic cracking (FCC) gasoline" elaborates the FCC additives prepared by impregnation and gives examples of such additives and their expected functions role in the in reducing sulfur in gasoline catalytic cracking processes. Another paper titled "Development of hydro-treating catalysts with improved performance" underlines the major improvements of the catalysts for deep HDS of gas oils derived from heavy crudes, indicative of overwhelming influence of refractive sulfur species on the overall HDS. Besides, another innovative work done by J. Zhao et al. is the bifunctional catalysts for upgrading FCC gasoline by coupling reactive adsorption desulfurization and aromatization of olefins (RADS-Ar).
It is known that industrial FCC plants always run with high operating costs and at the fast-fluidized bed regime, concerning intricate two-phase or three-phase flow behaviors and complicated catalytic cracking reactions. Thereby successful modeling simulation relying on the advanced computer makes it possible to estimate sophisticated flow reactions with higher accuracy, by which preliminary test costs might be greatly reduced in the foreseeable future. Paper titled "An Integrated Methodology for the Modeling of FCC Riser Reactor." by Y. Du described a novel methodology for modeling FCC riser reactor named equivalent reactor network model (ERN).

It is hoped that readers will find the papers in this special issue of interest, usefulness and stimulation in their relevant research. We appreciate all authors and referees for their scientific contributions to the publication of this special issue. Last but not least, we would like to express our gratitude to the editors of Applied Petrochemicals Research and the journal manager for their strong support and wonderful assistance.

Open Access This article is distributed under the terms of the Creative Commons Attribution License which permits any use, distribution, and reproduction in any medium, provided the original author(s) and the source are credited. 